\title{
A Performance Investigation and Comparison of Line Start-up Permanent Magnet Synchronous Motor with Super Premium Efficiency
}

\author{
X. Feng*, Y. Bao*, L. Liu**, L. Huang**, and Y. Zhang**
}

\begin{abstract}
This paper presents the performance investigation and design technology of a Line Start-up Permanent Magnet Synchronous Motor (LSPMSM) with super premium efficiency, including a design consideration and evaluation for motor start-up, key performance, and advanced finite element analysis FEA) for the design, improvement and verification, prototype build and test, design and test data comparison with a Premium ${ }^{\circledR}$ Efficient Induction Motor (PEIM). To assess the design technology, the LSPMSM prototype was built amended from a PEIM with the same frame, stator punching and rated output. Based on the prototype test, two novel design improvements and analyses have been done to eliminate noise and vibration. Additionally, the comparisons with the PEIM on the power factor, efficiency, frame size and active material consumption indicated that a significant performance improvement and active material cost reduction can be achieved by the LSPMSM.
\end{abstract}

Keywords: Line Start-up Permanent Magnet Machine, Synchronous Machine, IE4 Efficiency

\section{Introduction}

Electric machines are widely used in various industries to transfer the energy between electric sources and mechanical functions. About $40 \%$ of electric energy consumption is used up by motors (Fig. 1) [1]. Therefore, the efficiency of the motor is very important for long-time energy saving policy. The Premium ${ }^{\circledR} /$ IE3 Efficient Induction Motor (PEIM) has an even higher efficiency level. For the past years, the International Electrotechnical Commission (IEC) has introduced a new standard relating to more efficient motors called International Efficiency level 4 (IE4) and level 5 (IE5). It has recommended the losses of induction motor with IE4 efficiency should be $10 \sim 15 \%$ less compared with the PEIM (Fig. 2) [1]. Some manufacturers try to reduce induction motor losses using the copper squirrel cage and more materials. However, the high melting point of copper can cause some trouble in the rotor build.

For the past several years, the Line Start-up Permanent Magnet Synchronous Motor (LSPMSM) with super premium efficiency (IE4) has been researched, designed,

\footnotetext{
* Technology Center, TECO- Westinghouse Motor Company, USA

(fengjame@teco-westinghouse.com)

** TECO-Westinghouse Hangzhou R\&D Center, China

(ryan@teco-tech.com)

Received 24 December 2011; Accepted 27 January 2012
}

built and tested. Based on the test results of first LSPMSM prototype and with advanced Finite Element Analysis

(FEA), two novel motor configurations are introduced and their mechanical and electrical performances including starting performance, noise and vibration have been scrutinized. Additionally, compared with the PEIM, the material consumption, efficiency, power factor, starting torque, temperature rise, etc., are much better over the wide range of output power. Also, the LSPMSM can start up and run at constant-speed without a Variable Frequency Driver (VFD) and run at variable speeds with a simple standard (volts/hertz) VFD without a position sensor. Thus, it should be a general-purpose motor that can replace the existing PEIM for a wide range of line start-up and variable-speed applications.

\section{Performance Investigation and Challenge}

Compared with the PEIM, the LSPMSM has a lot of advantages: synchronous speed, higher power factor and efficiency, small size, wide speed range of economic running, etc. Like the conventional synchronous motor, in addition to steady running parameters such as: rated power, torque, speed, power factor, and efficiency, special design challenges are focused on: starting performance, such as noise and vibration, starting torque and current, 
pull-in torque, minimum torque, and pull out torque, etc. Based on the noise and vibration problem on the starting up test of the first LSPMSM prototype, special focus is on the cogging torque which may cause much more noise and vibration when the motor is starting-up. Two main actions: closed slot and skew slot, are taken to reduce the cogging torque caused by stator and rotor open slots. The different slot skew in the motor are analyzed. The best one is used in the second LSPMSM prototype design, build and test.

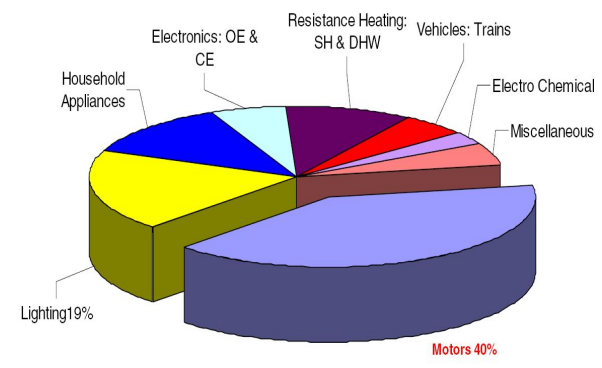

Fig. 1. Electric consumption

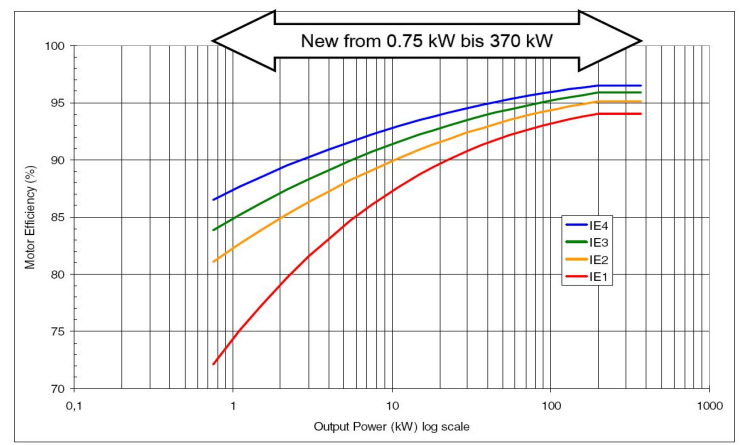

Fig. 2. New energy efficiency levels

\subsection{Rotor Configuration}

Normally, The LSPMSM uses an inner rotor configuration combined by squirrel-cage used to start-up the motor and permanent magnet poles to obtain electromagnetic torque as synchronous running. The stator and winding is similar as an induction machine or a traditional synchronous machine. The squirrel cage in the rotor is normally mounted at the outside of the rotor to increase starting torque. There are different permanent magnet bulk arrangements to figure out the different rotor configurations: the parallel magnetic path, the series magnetic path and the combined magnetic path. The principal of the rotor configuration choice is made as simple as possible to meet with output power and performance. Our new $7.5 \mathrm{~kW}$ prototype design of LSPMSM uses the rotor configuration with a series magnetic path (Fig. 3), in which, (a) is with semi-closed rotor slot and (b) with fully-closed rotor slot [3].

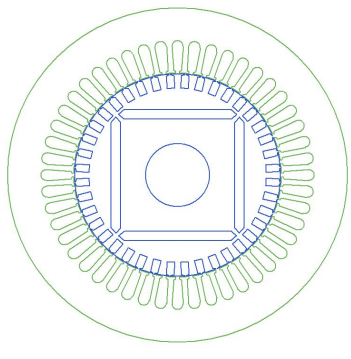

(a) Semi-closed rotor slot

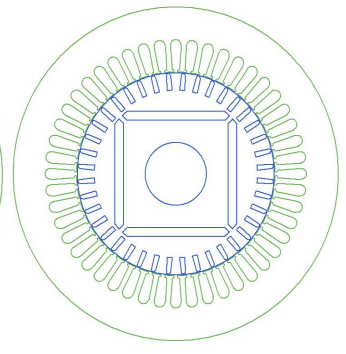

(b) Fully-closed rotor slot
Fig. 3. Stator and rotor configuration

\subsection{Starting-up Performance}

There are two combined rotating magnetic fields: one is excited by the balanced stator three phase current and another one is caused by the permanent magnet in the rotor during the LSPMSM machine starting-up. The total average torque during the motor starting-up includes the asynchronous torque produced by the squirrel-cage $\left(T_{i m}\right)$, the generator torque $\left(T_{g}\right)$ caused by the permanent magnet and the reluctance torque $\left(T_{r}\right)$ resulted from the different reluctance in the $\mathrm{d}$ - and q-axis. The minimum torque $\left(T_{\min }\right)$ during the motor starting-up is mainly contributed by the generator torque $\left(T_{g}\right)$ and the reluctance torque $\left(T_{r}\right)$. For most well designed line start-up permanent magnet synchronous motors, the minimum torque $\left(T_{\min }\right)$ is mainly dependant on generator torque $\left(T_{g}\right)$. It is clear that the generator toque is the function of $\mathrm{d}$ - and q-axis reactance, and slip and stator resistance.

It should be noted that the key evaluated torques in the motor starting-up processing are: starting torque $\left(T_{s}\right)$ as the rotor is blocked, minimum torque $\left(T_{\min }\right)$, maximum torque $\left(T_{\max }\right)$ and pull-in torque $\left(T_{p i}\right)$. Due to the high saturation and distortion of start current and magnetic field, these torques are very difficult to accurately evaluate with conventional analysis. The finite element analysis has to be applied to simulate the key start performance to ensure the motor can start up without any problem [2], [3].

\subsection{Cogging Torque}

With the development and improvement of the permanent magnet material characteristics, PM machines are more and more widely used in high performance control system and high efficiency applications. The cogging torque in the PM machine comes from variations in magnetic field density around a rotor's permanent magnets as they pass the non-uniform geometry of the slot openings in the stator and rotor. It is also known as detent or 'no-current' torque. This torque is position dependent 
and its periodicity per revolution depends on the number of magnetic poles and the number of teeth on the stator and rotor in the LSPMSM. Cogging torque is an undesirable component for the operation of such a motor. It is especially prominent at starting-up and lower speed, with the symptom of jerkiness. The cogging torque results in torque and speed ripple, noise and vibration. However, at high speed the motor moment of inertia filters out the effect of cogging torque. Therefore, the cogging torque minimization becomes a challenging task when the requirement is very stringent in applications such as electric power steering and robotics. In reality, the cogging torque may not be eliminated completely but minimized to a satisfactory level depending on the application requirements. A variety of techniques are available to reduce cogging torque in PM machines. Theoretically, all the techniques are quite effective for minimizing the cogging torque. Some of the known effective techniques for reducing the cogging torque are: skewing stator stack or magnets, optimizing the stator and rotor slot opening, using fractional slots per pole per phase, modulating drive current waveform, optimizing the magnet pole arc or width, selecting good stator and rotor slot and pole combination, etc. Also, slotless PM machines do not have any cogging torque. However, almost all of the techniques used against cogging torque also reduce the motor EMF_and so reduce the resultant running torque. Very large noise and vibration have been found in the starting-up test for our $7.5 \mathrm{~kW}$ and $950 \mathrm{~kW} 4$ pole LSPMSM prototypes. Therefore, some effective technique has to be used to eliminate the torques resulting in noise and vibration when a LSPMSM is starting-up. Unfortunately, classical electromagnetic calculations do not provide the data needed to determine how much various torques might develop in a new design. Although a complete finite-element analysis may be an alternative to manual methods, it usually requires more project time than is available.

\subsection{Other Performance Investigations and Challenges}

The no-load magnetic flux leakage coefficient $\left(K_{l}\right)$ is the ratio of the total flux produced by magnet bulks to the flux passed through air gap in one pole. This coefficient is more important for the design of a LSPMSM and it is composed of two parts: the flux leakage coefficient at the inside and the end of the rotor. There is slot flux leakage and the flux leakage caused by magnetic insulation bridges in the rotor. Because the rotor configuration of LSPMSM is more complex, the best way to get an accurate flux leakage coefficient is using FEA. The more flux leakage, the more permanent magnet material has to be used. Normally, the value of 1.05 to 1.45 is applied to a LSPMSM design, depending on the rotor configuration.

There are two components in the electromagnetic power/torque: the first item is the permanent magnet power/torque and the second one is the reluctant power/torque. Compared with a conventional electrical excited salient pole synchronous motor and due to an existing permanent magnet in the d-axis pathway, normally the q-axis reactance of the permanent magnet synchronous motor with an inner magnet rotor configuration is larger than the d-axis reactance $\left(X_{q}>X_{d}\right)$. This means that the reluctance power/torque should be negative as the power angle moves from $0^{\circ}$ to $90^{\circ}$. Therefore, the power angle $\theta_{\max }$ at maximum running power $\left(P_{\max }\right) /$ torque $\left(T_{\max }\right)$ should be more than $90^{\circ}$. Negative power/torque may occur when power angle is too small. Therefore, a minimum power angle $\left(\theta_{\min }\right)$ of a design for a permanent magnet synchronous motor should meet with:

$$
\theta_{\min }>\arccos \left[\frac{E_{0}}{V}\left(\frac{X_{q}}{X_{q}-X_{d}}\right)\right]
$$

In general, the permanent magnet synchronous motor should be designed to run at a power angle from a minimum power angle $\left(\theta_{\min }\right)$ to a maximum power angle $\left(\theta_{\max }\right)$. This is also called the stable running range. Normally, the rated running power angle $\left(\theta_{N}\right)$ should be from $40^{\circ}$ to $60^{\circ}$ and the maximum power angle $\left(\theta_{\max }\right)$ should be from $105^{\circ}$ to $125^{\circ}$ for an LSPMSM with an inner PM rotor. But for an LSPMSM with a surface mounted PM rotor, the rated running power angle $\left(\theta_{N}\right)$ should be from $20^{\circ}$ to $35^{\circ}$ and the maximum power angle $\left(\theta_{\max }\right)$ should be about $90^{\circ}$.

Permanent magnet material can be demagnetized due to high temperature, a strong demagnetizing magnetic field, etc. The designed LSPMSM should be justified by the demagnetizing effect on the motor. The following formula is applied to verify the demagnetizing of permanent magnet in the motor [2],[3]:

$$
b_{m d}=\frac{\lambda_{e x}\left(1-K_{a d m}\right)}{1+\lambda_{e x}}
$$

Where $b_{m d}$ is maximum demagnetizing point; $\lambda_{\text {ex }}$ is the total permeance of the external magnetic circuit; $K_{a d m}$ is the magnetic configuration coefficient.

For the rotor configuration with a series magnetic path, $K_{a d m}$ should be:

$$
K_{a d m}=\frac{0.045 m K_{a d} K_{w} N I_{a d m}}{p K_{l} H_{c b} h_{m}}
$$

For the rotor configuration with a parallel magnetic path, $K_{\text {adm }}$ can be given as: 


$$
K_{a d m}=\frac{0.09 m K_{a d} K_{w} N I_{a d m}}{p K_{l} H_{c b} h_{m}}
$$

Where $m$ is the number of phases, $K_{a d}$ is the d-axis armature reaction factor, $K_{w}$ is the stator winding factor, $N$ is the number of turns in the series, $I_{a d m}$ is the maximum daxis current, $p$ is the number of pole pairs, $K_{l}$ is the no-load magnetic flux leakage coefficient, $H_{c b}$ is the coercive force of the permanent magnet and $h_{m}$ is the width of the permanent magnet in the magnetizing direction.

For LSPMSM design, $b_{m d}$ should be more than the knee point of the demagnetizing curve of the permanent magnet under the highest running temperature condition. Normally, for the permanent magnet machine with an $\mathrm{F}$ class insulation system running at $\mathrm{B}$ class conditions, the motor maximum running temperature is $120^{\circ} \mathrm{C}, b_{m d}$ should be larger than 0.35 for $N d F e B-N 35 H$ material. Also, the demagnetizing of the machine in the worst case scenario can be evaluated by FEA.

\section{Finite Element Analysis Evaluation}

Due to the complex rotor configuration of an LSPMSM, it is not easy to obtain more accurate designed performance from conventional analysis. Advanced electrical and mechanical finite element analysis (FEA) has to be applied for more accurate result evaluations during the design stage. Normally, more considerations are concentrated on starting-up performance, cogging torque elimination, rotor mechanical stress, thermal flow and temperature rise, no-load voltage and harmonics, and dand $\mathrm{q}$-axis reactance etc. The results from FEA show the good performance of the designed prototype and better coincidence of the results from FEA and analysis formulas.

\subsection{Starting-up Performance}

The starting-up performance of an LSPMSM is very important to run the motor from stillness to synchronous speed. The rotor squirrel-cage is used to get asynchronous positive start torque same as induction motor. On the contrary, the permanent magnet in the rotor brings out a negative torque called generator torque, which resist the rotor to speed-up. Also, some other torques such as reluctant torque, harmonic torque, etc. may be useful or harmful for the motor to start-up. During the motor starting-up, it is easy to get enough maximum torque $\left(T_{\max }\right)$ for motor start-up. Therefore, the start torque $\left(T_{s}\right.$ at slip $s=1)$, minimum torque $\left(T_{\min }\right)$ and pull-in torque $\left(T_{p i}\right)$ are much more important and they are very difficult to evaluate accurately with conventional analysis during the design stage because of high saturation and distortion of the start current and magnetic field. In same way, digital simulation FEA has to be applied to the $7.5 \mathrm{~kW}$ and $950 \mathrm{~kW}$ LSPMSM designs.

Figs 4 and 5 show the starting-up speed and torque performance for the $7.5 \mathrm{~kW} 4$ pole prototype. From FEA results, there is a lager negative torque as the rotor starts up, which results in noise and vibration while the rotor holds still or runs at low speed. Also, the test data of $950 \mathrm{~kW}$ and $7.5 \mathrm{~kW} 4$ pole LSPMSM prototypes showed that a lot of noise and vibration occurred as the prototypes starting up. The reason for this LSPMSM noise and vibration is more complicated. The necessary research and

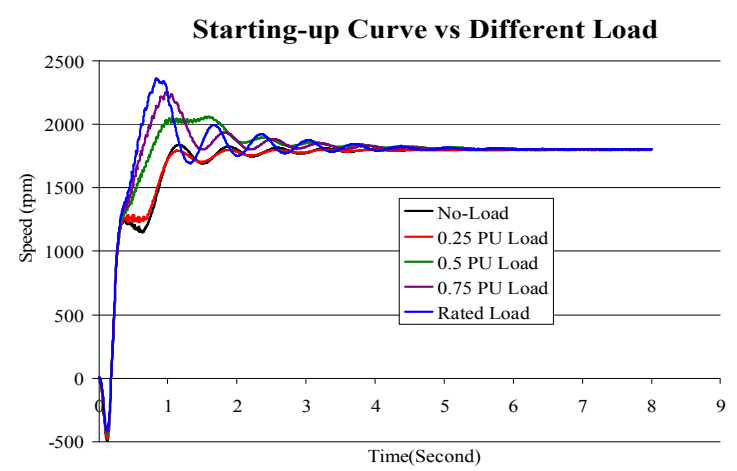

Fig. 4. Starting-up speed (FEA)

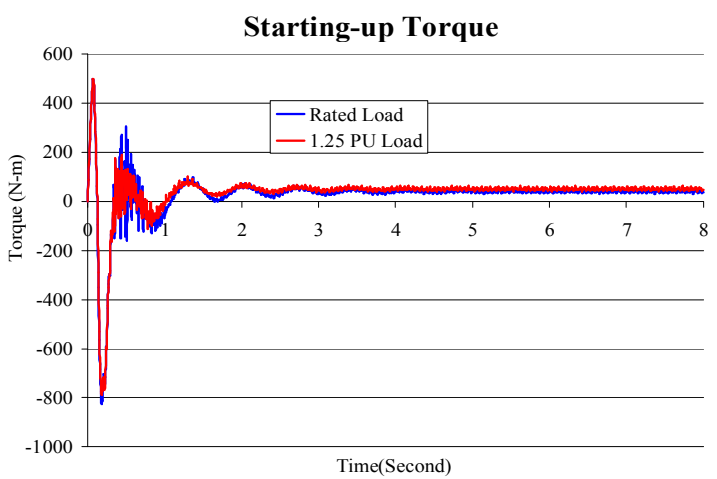

Fig. 5. Starting-up torque (FEA)

design improvements are under way to reduce the noise and vibration of the LSPMSM starting-up process.

\subsection{Cogging Torque}

As mentioned above, cogging torque results in torque and speed ripple, noise and vibration. Some of the known effective techniques for reducing cogging torque are: skewing stator stack or magnets, optimizing the stator and rotor slot openings, using fractional slots per pole per phase, modulating the drive current waveform, optimizing the magnet pole arc and width, selecting a good stator and rotor slot and pole combination, etc. But almost all of the techniques used against cogging torque also reduce the motor counter-electromotive force and so reduce the 
resultant running torque. Therefore, some effective technique has to be used to eliminate the torque resulting in noise and vibration. Unfortunately, classical electromagnetic calculations do not provide the data needed to determine how much cogging torque might develop in a new design. Although a complete FEA may be an alternative tool, it usually requires more time than is available. In any case, skewing the magnets or the stator core often can lower cogging torque a bit more.

Based on the test data of the first $7.5 \mathrm{~kW} 4$ pole LSPMSM prototype, the rotor configurations have been improved as shown in Fig. 3 (a) and (b). The rotor in Fig. 3 (a) is a semi-closed rotor slot and (b) is a full-closed rotor slot configuration. Both LSPMSMs are built with the stator skew technique. Fig. 6 shows the cogging torque vs different stator slot skew from 0 pitch (no skew) to one full pitch (one stator slot skew) with a semi-closed rotor slot. The large cogging toque can be found if the machine has no stator slot skew and with a semi-closed rotor slot. There is almost no cogging torque if skews one stator slot. Also, a large cogging toque can be found in Fig. 7 if the machine has no stator slot skew with a full closed rotor slot. There is almost no cogging torque if skews one stator slot (one pitch). In addition, the maximum cogging torque comparison for both semi-closed and full-closed rotor slots is shown in Fig. 8.

Cogging Torque/Stator Slot Skew

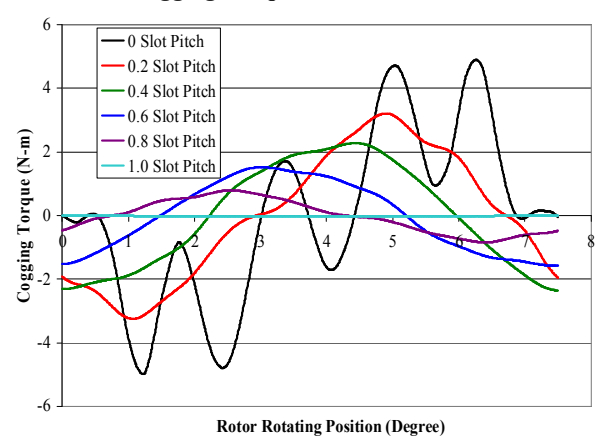

Fig. 6. Cogging torque vs stator slot skew (semi-closed rotor slot)

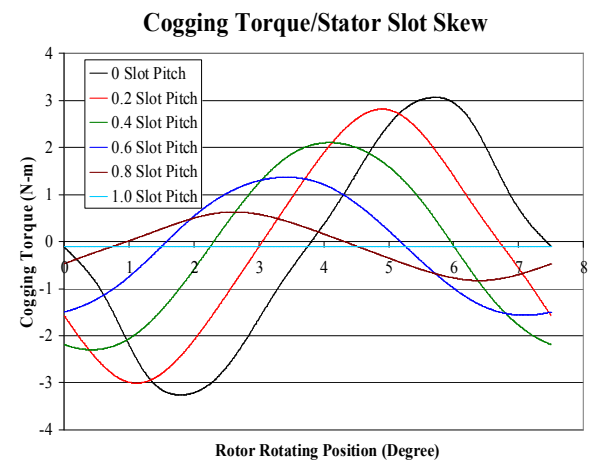

Fig. 7. Cogging torque vs stator slot skew (full-closed rotor slot)

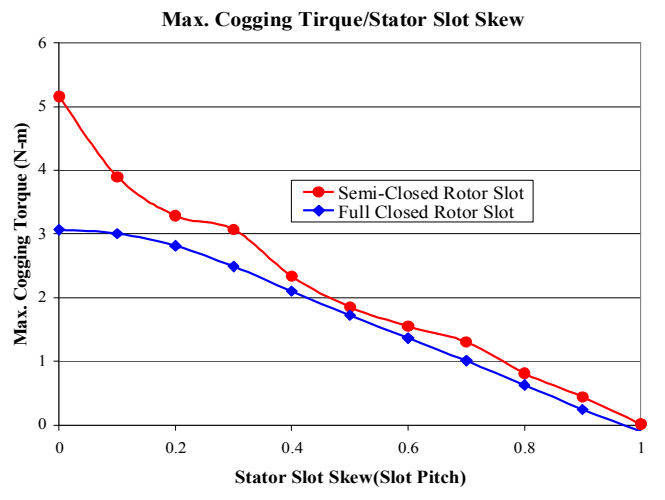

Fig. 8. Max. cogging torque vs stator slot skew

With the semi-closed and full-closed rotor slots, the difference of the maximum cogging torque is very close if stator slot skew is more than 0.2 of the slot pitch. The closed rotor slot results in more flux leakage and therefore more magnet material has to be used to keep enough flux density in the air gap. Therefore, the semi-closed rotor slot is used in the new prototype of $7.5 \mathrm{~kW} 4$ pole LSPMSM.

\subsection{Temperature Rise and Rotor Mechanical Stress}

For new permanent magnet electrical machine design and development, the thermal and temperature rise issues are more important to ensure the motor can run normally without stator winding damaged and permanent magnet demagnetized by high temperature. It is very difficult to figure out accurate thermal flow and temperature rise results from conventional analysis methods, especially for an LSPMSM due to the rotor complex configuration.

The advanced digital simulation technique has to be applied to evaluate the thermal flow and temperature rise for $7.5 \mathrm{~kW}$ and $950 \mathrm{~kW}$ prototype research and design [2], [5]. Fig. 9 shows the temperature distribution of the 4 pole $7.5 \mathrm{~kW}$ LSPMSM. As shown in the figure, the maximum temperature rise is $46^{\circ} \mathrm{C}$. It is much less compared with temperature rise limit (RTD $90^{\circ} \mathrm{C}$ at ambient $40^{\circ} \mathrm{C}$ ).

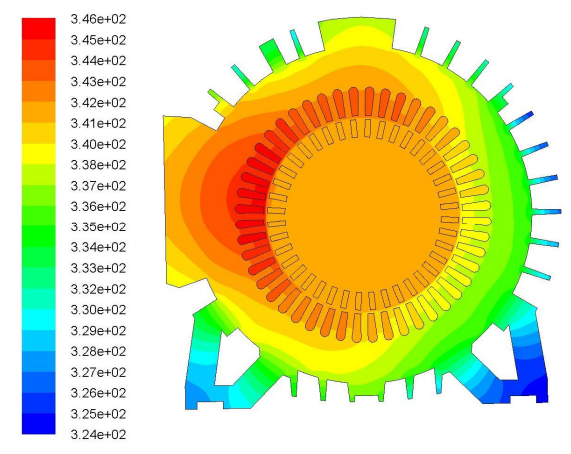

Fig. 9. Temperature distribution in 7.5kW LSPMSM 
Also, in various rotor configuration of the LSPMSM, the width of the magnetic insulation bridge in the rotor has a more important role for both motor electrical performance and mechanical stress, especially for high or super-high speed machines. The greater width of the magnetic insulation bridge means more rotor safety for mechanical stress issues. But greater width predicates more magnetic flux leakage and more permanent magnet material has to be used. For both of $7.5 \mathrm{~kW}$ and $950 \mathrm{~kW} 4$ pole LSPMSM prototype designs, the equivalent stress and shear stress analyses on the rotors have been done with commercial finite element analysis software [5]. Fig. 10 shows the equivalent stress distribution in the rotor of a $7.5 \mathrm{~kW} 4$ pole LSPMSM running in the worst case scenario.

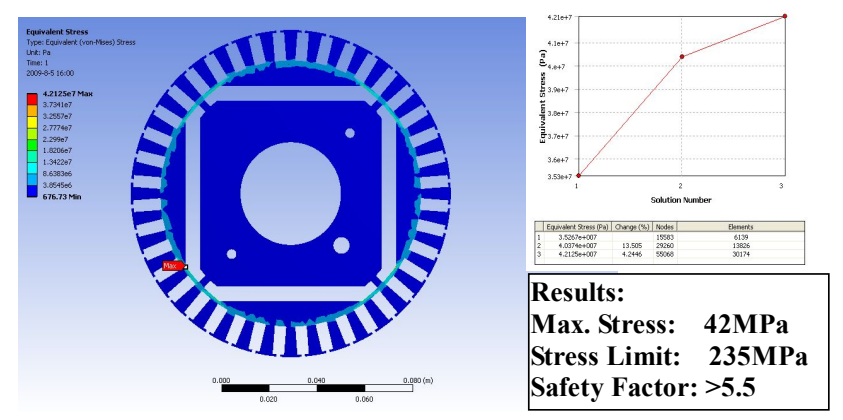

Fig. 10. Equivalent stress distribution in rotor

The maximum equivalent stress is $42 \mathrm{MPa}$ and the stress limitation of the rotor material is $235 \mathrm{MPa}$. Therefore, the rotor equivalent stress safety factor is more than 5.5.

\section{Performance and Material Usage Comparison}

To verify the theory, design consideration and evaluation, key parameters and performance, an LSPMSM prototype was built and tested. Some test data such as fullload temperature rise, starting-up and running performance, etc., were listed in [2]. Also, the tested power factor, and efficiency were compared with designed data and properties of a PEIM under different output power. The compared PEIM has the same frame size, speed, rated voltage and output power, but has a longer core length than the LSPMSM prototype. Meanwhile, the main performance and material consumption of the optimized 4 pole LSPMSM with 25HP output power is compared with the PEIM. Much better performance and material consumption down to $60 \%$ can be found in the improved 25HP 4 pole LSPMSM design.

\subsection{Performance Comparison}

For the first LSPMSM $7.5 \mathrm{~kW} 4$ pole prototype, the running performance and starting-up performance have been tested and recorded. The key data was obtained and compared as shown in Table 1 and 2. The running performance is very close between the design data and test data. However, large errors of comparison for the starting torque and maximum torque can be found. As such, conventional analysis should make more improvements to get better accurate starting performance.

Table 1. Running performance comparison

\begin{tabular}{|c|c|c|c|c|}
\hline $\begin{array}{c}\text { Running } \\
\text { Performance }\end{array}$ & $\begin{array}{c}\text { Startor } \\
\text { Current (A) }\end{array}$ & $\begin{array}{c}\text { Efficiency } \\
(\%)\end{array}$ & $\begin{array}{c}\text { Poert } \\
\text { Factor }(\%)\end{array}$ & $\begin{array}{c}\text { Stator } \\
\text { Resistance } \\
(\Omega) \text { at 22C }\end{array}$ \\
\hline Test & 20.2 & 93.7 & 99.3 & 0.9111 \\
\hline Design & 20.45 & 93.3 & 98.7 & $\mathbf{0 . 9 1 7 4}$ \\
\hline Different & $-1.22 \%$ & $0.43 \%$ & $0.61 \%$ & $\mathbf{- 0 . 6 9 \%}$ \\
\hline
\end{tabular}

Table 2. Starting-up performance comparison

\begin{tabular}{|c|c|c|c|c|}
\hline $\begin{array}{c}\text { Starting } \\
\text { Performance }\end{array}$ & $\begin{array}{c}\text { Start } \\
\text { Current (A) }\end{array}$ & $\begin{array}{c}\text { Starting } \\
\text { Torque (PU) }\end{array}$ & $\begin{array}{c}\text { Minimum } \\
\text { Torque (PU) }\end{array}$ & $\begin{array}{c}\text { Maximum } \\
\text { Torque (PU) }\end{array}$ \\
\hline Test Data & 187 & $\mathbf{3 8 2} \%$ & $125 \%$ & $264 \%$ \\
\hline Design Data & 183.7 & $251 \%$ & $122 \%$ & $337 \%$ \\
\hline Different & $1.80 \%$ & $\mathbf{5 2 . 2 0} \%$ & $\mathbf{2 . 4 6} \%$ & $-21.66 \%$ \\
\hline
\end{tabular}

Table 3 shows calculated starting-up performance data and comparison between two different analysis methods for the new $7.5 \mathrm{~kW} 4$ pole LSPMSM prototype design. A good concordance with each other can be found in Table 3.

Table 3. Starting-up performance comparison

\begin{tabular}{|c|c|c|c|}
\hline $\begin{array}{c}\text { Calculated } \\
\text { Data (PU) }\end{array}$ & $\begin{array}{c}\text { Start Torque } \\
\left(T_{S}\right)\end{array}$ & $\begin{array}{c}\text { Minimum } \\
\text { Torque }\left(T_{\min }\right)\end{array}$ & $\begin{array}{c}\text { Pull-in Torque } \\
\left(T_{p i}\right)\end{array}$ \\
\hline $\begin{array}{c}\text { Conventional } \\
\text { Analysis }\end{array}$ & 2.78 & 1.48 & 1.14 \\
\hline FEA Method & 2.56 & 1.42 & 1.20 \\
\hline
\end{tabular}

\subsection{Comparison with Premium ${ }^{\circledR}$ Efficient (IE3) IM}

The tested and designed power factor, and efficiency for the $7.5 \mathrm{~kW} 4$ pole LSPMSM prototype have been compared with Premium ${ }^{\circledR}$ efficient (IE3) induction motor under different output power. The compared Premium ${ }^{\circledR}$ efficient (IE3) induction motor has same frame size, speed, rated voltage and output power, etc. but a longer core length than LSPMSM.

Fig. 11 shows the power factor comparison of the PEIM (IE3) and the LSPMSM (IE4) from 0.2PU to 1.25PU of output power. The tested power factor of the LSPMSM is very close to designed data but the power factor of the Premium ${ }^{\circledR}$ efficient (IE3) IM is much lower compared with the LSPMSM, especially in the range of low output 
power. This means that the LSPMSM can achieve a very high power factor $(>0.96)$ in a wide output power range. The high power factor in a wide output power range is very useful to save energy as the motor is running at different loads.

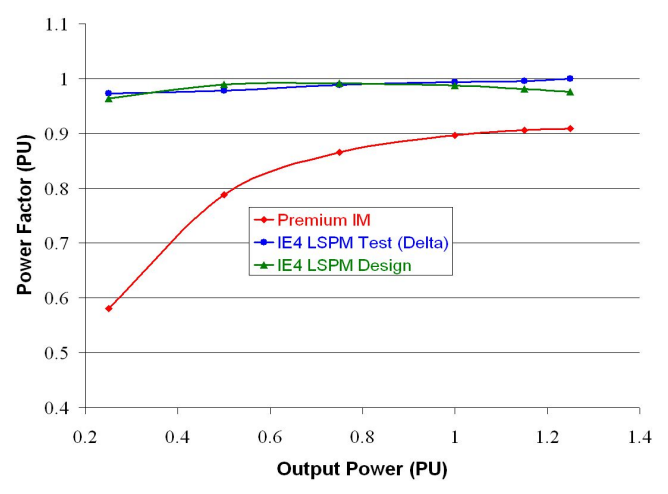

Fig. 11. Power factor comparison

Fig. 12 shows the efficiency comparison of the Premium $^{\circledR}$ efficient (IE3) IM and the LSPMSM from $0.2 \mathrm{PU}$ to $1.25 \mathrm{PU}$ of output power. The tested efficiency of the LSPMSM is higher than the designed data but the efficiency of the Premium ${ }^{\circledR}$ efficient (IE3) IM is much lower compared with the LSPMSM. This means that the LSPMSM can easily achieve super premium efficiency (IE4) over a wide output power range. The super premium efficiency over a wide output power range is very useful for saving energy as the motor is applied to industry applications.

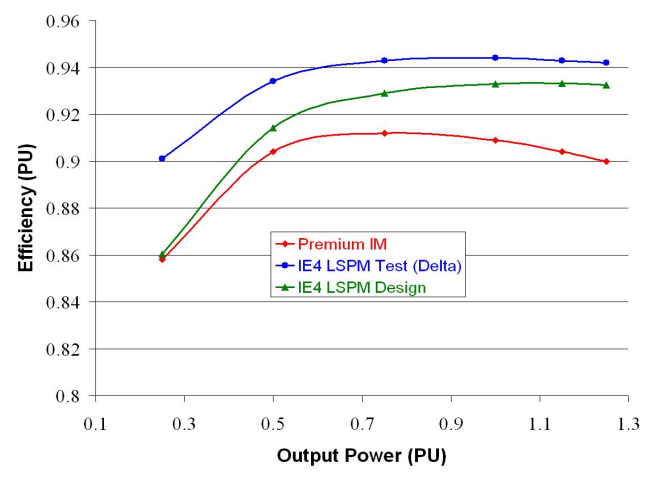

Fig. 12. Efficiency comparison

\subsection{LSPMSM Optimized Design and Comparison}

The $7.5 \mathrm{~kW}$ LSPMSM prototype has been built, tested and has shown very good performance compared with the PEIM/IE3 with same frame size and output. Especially, its efficiency has exceeded the IEC suggested super premium efficiency (IE4) level. The output power, speed, and frame size of the $7.5 \mathrm{~kW} / 10 \mathrm{HP}$ prototype are based on a NEMA standard PEIM. As per LSPMSM design, analysis and test, it is clear that with same output power and speed and higher power factor, the smaller frame size can be used for LSPMSM design. To make a comparison using the same output power and pole number, a $19 \mathrm{~kW} / 25 \mathrm{HP} 4$ pole LSPMSM with super premium efficient and a high power factor has been optimized. The main performance, frame size and material usage are compared with a $19 \mathrm{~kW} / 25 \mathrm{HP}$ PEIM and are shown in Table 4. A very good performance level can be found for the $19 \mathrm{kw} / 25 \mathrm{HP}$ LSPMSM.

Table 4. LSPMSM comparison with PEIM (19kW/25HP)

\begin{tabular}{|c|c|c|}
\hline $\begin{array}{c}\text { 25HP 4 Pole } \\
\text { Performance }\end{array}$ & LSPMSM(IE4) & $\begin{array}{c}\text { Premium }{ }^{\circledR} \\
\text { IM(IE3) }\end{array}$ \\
\hline Efficiency & $\mathbf{9 5 . 8 \%}$ & $\mathbf{9 3 . 9 \%}$ \\
\hline Power Factor & $\mathbf{9 7 . 0 \%}$ & $\mathbf{8 9 . 8 \%}$ \\
\hline Starting Torque (PU) & $\mathbf{2 3 6 . 0 \%}$ & $\mathbf{1 3 2 \%}$ \\
\hline Starting Current (A) & $\mathbf{2 5 2 . 5}$ & $\mathbf{2 9 0 . 7}$ \\
\hline Minimum Torque (PU) & $\mathbf{1 1 5 . 0 \%}$ & $\mathbf{1 3 2 \%}$ \\
\hline Maximum Torque (PU) & $\mathbf{2 6 5 . 0 \%}$ & $\mathbf{2 5 3 \%}$ \\
\hline Pull-In Torque (PU) & $\mathbf{1 2 6 . 8 \%}$ & N/A \\
\hline
\end{tabular}

Table 5 shows the material consumption for both the LSPMSM and the PEIM with $19 \mathrm{~kW} / 25 \mathrm{HP}$. It is clear that besides the fact that $19 \mathrm{~kW} / 25 \mathrm{HP}$ LSPMSM has a smaller frame size, the consumptions of core lamination, winding copper and cage aluminum of the $19 \mathrm{~kW} / 25 \mathrm{HP}$ LSPMSM are about $60 \%$ of the consumption in the $19 \mathrm{~kW} / 25 \mathrm{HP}$ PEIM. However, $3.55 \mathrm{~kg}$ NdFeB N35H permanent magnet material has to be used in this LSPMSM. Hopefully, the cost of PM material in a $19 \mathrm{~kW} / 25 \mathrm{HP}$ LSPMSM may be reimbursed by frame and material reductions.

Table 5. Material consumption comparison (19kW/25HP)

\begin{tabular}{|c|c|c|c|}
\hline $\begin{array}{c}\text { 25HP 4 Pole Material } \\
\text { Consumption }\end{array}$ & $\begin{array}{c}\text { LSPMS } \\
\text { M(IE4) }\end{array}$ & $\begin{array}{c}\text { Premium }{ }^{\circledR} \\
\text { IM(IE3) }\end{array}$ & Ratio \\
\hline Core Laminations & $82.9 \mathrm{~kg}$ & $124.4 \mathrm{~kg}$ & $66.6 \%$ \\
\hline Winding Copper & $11.2 \mathrm{~kg}$ & $21.9 \mathrm{~kg}$ & $51.2 \%$ \\
\hline Cage Aluminum & $1.86 \mathrm{~kg}$ & $3.61 \mathrm{~kg}$ & $\mathbf{5 5 . 5 \%}$ \\
\hline NdFeB PM Material & $3.55 \mathrm{~kg}$ & N/A & N/A \\
\hline Frame Size & F254T & F284T & $\begin{array}{l}\text { One Size } \\
\text { Smaller }\end{array}$ \\
\hline
\end{tabular}

\section{Conclusions}

The super premium efficient LSPMSM prototype was investigated, developed, tested and optimized. The challenges and key design techniques were introduced. The advanced digital simulation was used for the design validation and performance evaluation. Compared to a PEIM, the test results of the LSPMSM showed much higher efficiency, power factor, and power density, as well as a smaller frame size and less material consumption. After the rotor and stator slots are optimized, the starting performance should be considerably improved. 


\section{Acknowledgements}

The authors gratefully acknowledge the contributions of J. Kang, S. Huang and L. Lin for their work on the prototype build and test.

\section{References}

[1] C. U. Brunner, "Efficient Electric Motor Systems in Industry", IEA in Deployment of Demand Side Technologies, Paris, France, Oct. 2007

[2] X. Feng, L. Liu, J. Kang, Y. Zhang, "Super Premium Efficient Line Start-up Permanent Magnet Synchronous Motor," in Proc. of XIX International Conference on Electrical Machines, ICEM 2010, Roma, Italy, Sept. 6-8, 2010

[3] L. Liu, Y. Zhang, L. Huang, X. Feng, "Report on Design and Development of Supper Premium Efficient Line Start-up Permanent Magnet Synchronous Motor," Interior Report and Presentation on LSPMSM Project at Teco-Westinghouse Motor Company, May 2011, Round Rock, Texas, USA

[4] MagNet Software v7 2D/3D User's Manual, Infolytica Corporation. 2009

[5] ANSYS Software User's Guides, ANSYS Inc., 2009

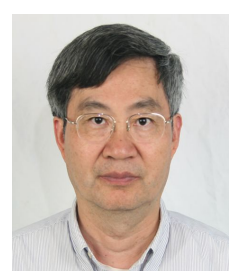

Xueqing Feng graduated from the Faculty of Engineering, Katholieke Universiteit Leuven, Leuven, Belgium with Doctorate and Master's degree, and from Shanghai Jiaotong University, China with a Master's degree. His special fields of interest are electrical machine a and control.

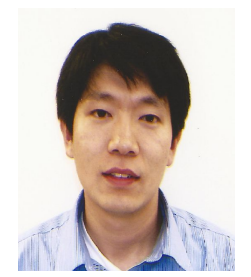

Yaxin Bao graduated from Tianjin University, China with BSME degree and from University of Missouri-Rolla with an MS degree. His research interests are electric machines, fault diagnosis and rotor-dynamic analysis.

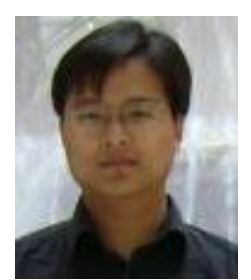

Lijun Liu received M.S. degree in electrical engineering from Harbin University of Science \& Technology, China. His research interests are electrical machines and digital simulation.

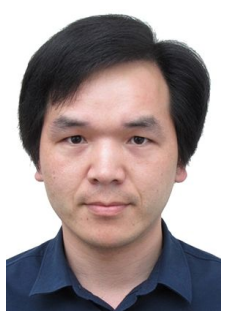

Lizhong Huang received M.S. degree in mechanical engineering from Qinghua University, China, His research interests are thermal and flow in electrical machines.

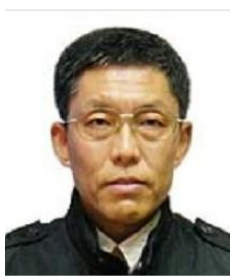

Yingming Zhang received Doctorate and M.S. degree from Xi'an Jiao tong University, China. His research interests are electrical machine design and FEA analysis. 